\title{
Do sustainability measures constrain urban design creativity?
}

Joanne M. Leach MSC

Research Fellow, Civil Engineering, University of Birmingham, Birmingham, UK

Christopher T. Boyko PhD

Senior Research Fellow, ImaginationLancaster, Lancaster University, Lancaster, UK

Rachel Cooper OBE, PhD

Professor, ImaginationLancaster, Lancaster University, Lancaster, UK
Anna Woodeson BArch

Associate Director, Wilkinson Eyre Architects, London, UK

Jim Eyre OBE, Dip Arch

Director, Wilkinson Eyre Architects, London, UK

Christopher D. F. Rogers PhD

Professor, Civil Engineering, University of Birmingham, Birmingham, UK

Planners, architects, urban designers and other built environment professionals engage with a myriad of checkboxes, guidelines, requirements and specifications, all of which potentially compromise creativity and innovation in urban design. Approaches that measure performance are accused of belying the nature of places as messy, plural, organic, accidental and emotive; trying to find a formula that works may tick boxes, but it risks creating soulless spaces, oppressing innovation and incorporation of inappropriate design elements. This paper argues that sustainability assessment methods do have something to contribute to creativity and innovation in urban design precisely because they encourage engagement with challenging and often complex societal priorities. Through interviews with built environment professionals and a critical examination of sustainability assessment methods, the authors suggest that such methods can promote creativity and innovation if they engage competently with sustainability, work at a scale that allows for both breadth and depth (typically greater than the building scale) and incorporate in their design a set of eight key characteristics designed to promote creativity and innovation.

\section{Introduction}

In 2005, Urban Task Force, the UK body charged with setting out a vision for the renaissance of cities, stated that, 'the majority of new developments remain poorly designed, with public realm and buildings of a very low quality' and that 'too many housing projects ... often lack the core social and commercial institutions that sustain urban life and any sense of place or beauty' (Urban Task Force, 2005, p. 5). They believed that design quality was not considered a priority by the public sector, nor was design culture properly embedded in procurement and management processes. Since this time, government and local authorities have attempted to bring design quality to the foreground within urban design, planning and sustainability (e.g. ODPM, 2005). What has often happened, however, is that the arising guidelines and assessment methods, which aim to improve design quality, rigidly and restrictively quantify or objectify urban design into a series of tick boxes, indicators and normative requirements for the sake of efficiency, thus negatively impacting the quality of urban design by constraining creativity and innovation (Kelbaugh, 2002).

Rather than view guidelines, assessment methods and their ilk as hindering creativity and innovation in urban design, this paper suggests that, if properly embraced, such approaches actually may promote these attributes by facilitating opportunities to engage directly with complex issues, such as sustainability, resilience and liveability. Furthermore, there are opportunities for guidelines, assessment methods and specifications to enhance creativity and innovation by incorporating characteristics that promote these attributes. In this paper the authors investigate the following research questions: Do sustainability assessment methods encourage or hinder creativity and innovation in urban design? How can they encourage creativity and innovation?

The methodology used in conducting the research is first outlined in the following section. In Section 3, the authors summarise urban design - it is here that the tension between fostering creativity and innovation, and the requirement to follow established procedures, is first highlighted. The fourth section introduces sustainability assessment methods and establishes their relationship with urban design. In Sections 5 and 6, eight key characteristics that promote creativity and innovation are derived, and their presence or absence in a selection of 32 sustainability assessment methods is assessed. Section 7 then draws together and summarises the above content, and the paper concludes with the formulation of a 
principle for promoting and enhancing creativity and innovation in sustainability assessment methods.

\section{Methodology}

The authors conducted eight interviews with nine UK built environment professionals (two were interviewed together): two architects, two design and engineering consultants, four sustainable development consultants and one urban designer. Two of the nine interviewees have multiple professional roles, although for the purpose of this paper the interviewees' primary current roles were used. This group was selected because urban design is informed by a breadth of professions, rather than solely by urban designers (Lombardi et al., 2011). Interviews were typically an hour in duration and (with two exceptions) both lead authors were present. Semi-structured interviews were employed, comprising seven questions plus supplementary questions when necessary (e.g. to clarify issues), as listed below.

(a) What does urban design mean to you?

(b) What promotes innovation and creativity in urban design?

(c) What techniques or methods do you use to encourage innovative and creative urban design, both yourself and in others?

(d) Do you think the trend towards designing sustainable places offers designers an opportunity for creativity and innovation?

(e) What is your experience of sustainability assessment methods?

(f) Do sustainability assessment methods promote or hinder creativity and innovation in urban design? Specifically which ones... good and bad... and why?

(g) Are there any urban design assessment methods in addition to those mentioned in this interview that you wish us to note?

Immediately following each interview a summary was compiled and validated by the interviewee. The summaries were analysed for information related to the study's two primary constructs: (a) characteristics of creativity and innovation, and (b) engagement with complex issues (i.e. sustainability). A content analysis of the summaries was conducted to identify additional themes.

In this way, the built environment professionals determined which sustainability assessment methods were to be examined, as well as which relevant characteristics to investigate. It should be noted that the interviewees were not asked to define concepts, such as 'good', 'quality' or 'sustainability' during interviews; rather, they focused on barriers to creativity and innovation in relation to addressing dimensions of sustainability to achieve their own notions of 'good' and 'quality'.

\section{Defining urban design}

From its beginnings in the 1950s as a confluence of architecture, landscape architecture and town planning (Frey, 1999; Krieger, 2008; Mumford and Sarkis, 2008; Schurch, 1999), urban design has grown and matured into something more than just designing places that look good (see Cuthbert (2010) for a discussion about who established urban design and when it was established, and Frey (1999) for a discussion of how urban design should not be a discipline in its own right). Dimensions of urban design include relationships between people and between people and places (DETR and CABE, 2000; Mumford and Sarkis, 2008); the spirit of place (Norberg-Schulz, 1979); satisfying practical and emotional needs (Mumford and Sarkis, 2008); ordering the future, but not necessarily creating utopian futures (Kreditor, 1990); the dynamic features of space and time (DETR and CABE, 2000; Lynch, 1981; Mumford and Sarkis, 2008); how the physical parts of the built environment create networks of spaces and activities, which, in turn, have social roles (CABE and DETR, 2001); creating places that all citizens enjoy and with which they identify (Buchanan, 1988; Lai, 1988); the integration of humans and nature (Colman, 1988; Ellin, 2013); and the response to urban change and development (Barnett, 1982; Rowley, 1994). These dimensions help in understanding what comprises urban design: it is 'the art and process of designing, creating, making and managing spaces and places for people' (Boyko et al., 2005; cf. Cuthbert (2011) and Marshall (2009) for a discussion about the lack of a broadly accepted definition).

Two themes emerge from these ideas and from within the urban design literature, both of which were supported by the interviews. First, that urban design is an art (Biddulph, 2012; CABE and DETR, 2001; Cowan, 2000; Floyd, 1978; Lynch, 1981; Moughtin et al., 2003; Norberg-Schulz, 1979). The 'design' part of urban design suggests a link with the arts and humanities (Biddulph, 2012), especially the notions of creativity and innovation (see Section 5 for definitions of these terms), which stem from synthesis and imagination. All nine interviewees acknowledged that urban designers must creatively apply their skill, ability, knowledge, craft, science and imagination, and may involve innovation and taking risks: 'Creativity seeps through the cracks, innovation breaks through' (design and engineering consultant 1, 5 September 2013). All the interviewees also acknowledged the limitations that working in urban design can place upon designers. For example, one interviewee suggested that compliance is perceived to be more important in the current linear UK planning system, allowing for innovation neither to seep nor break through (design and engineering consultant 2, 17 September 2013).

The second theme is that urban design is a process (Barnett, 1982; CABE and DETR, 2001; DETR and CABE, 2000; Frey, 1999; Gosling, 1984; Madanipour, 1997; Toon, 1988; Webber, 1988; see also Brown, 1971, 1990). Process is the framework, 
rules and guidelines that allow for the 'orchestration of the city's physical parts' (Frey, 1999, p. 16). Outlining a process for urban design, whether it is for policy or practice, means that the generic 'rules' will be known by decision makers and stakeholders. All the interviewees recognised the value of following an urban design process to ensure more desirable outcomes. Doing so could result in a more open and transparent way for understanding how decisions are made, for allowing creativity to be part of the process and for acknowledging the political context under which decisions are made (Biddulph, 2012). The challenge is to undertake a process that does not stifle creativity and innovation.

\section{Urban design and sustainability assessment methods}

Recent decades have seen growing influence of the principles of sustainable development upon urban designers, urban design, the built environment and users of the built environment. The Brundtland Commission (WCED, 1987), the 1992 Earth Summit in Rio and the establishment of Agenda 21 and in 1996 of UK Local Agenda 21 placed urban sustainability as a high priority for all levels of UK government as well as for the private and academic sectors. Good urban design became an integral part of building and maintaining sustainable communities, ensuring that the government's social, environmental and economic objectives were intimately tied with how places were designed and developed (ODPM, 2003, 2005). All but one of the interviewees reflected this thinking. However, when asked whether or not 'doing' sustainability, de facto, leads to good urban design, the interviewees were split: half said that urban designers would have engaged with sustainability if not pushed by external factors, such as legislation. The other half felt that the emphasis on adhering to sustainability standards seems to have allowed urban designers to address previously unconsidered issues.

Sustainability assessment methods, such as Breeam and Code for Sustainable Homes, are used to improve the sustainability of designed buildings and spaces up to and sometimes beyond legislative requirements (Barlow, 2011; DCLG, 2014). Although the interviewees acknowledged this, they believed it was difficult for urban designers to know what methods are available to them at what stages of the urban design process. In addition, questions arose about whether these methods stifled creativity and innovation due to their tick-box approach and normative aspects. Eight of the nine interviewees agreed with this statement: these methods contribute primarily to the technical aspects of sustainability, not to creativity. However, they also recognised that these methods provide a way for urban designers to engage with sustainability, a complex and fast-moving issue, providing information that could form the basis for creativity and innovation.
While scholars have identified more than 700 different sustainability assessment methods (see Deakin et al., 2002; Gil and Duarte, 2013; McCreadie, 2006; Poveda and Lipsett, 2011), over half the interviewees failed to directly reference specific methods until prompted by the interviewers (with an average of four methods mentioned per interviewee). Methods were often discussed as a seemingly homogeneous group. In all the interviews, aspects of assessment methods that were not attributed to specific methods were offered. These fell into two areas: method design and function, and method operation.

\subsection{Method design and function}

Positive comments focused on the ability of sustainability assessment methods to prompt thinking on issues that might not otherwise have been considered (e.g. elucidating and prioritising aspects of urban design that influence sustainability, breaking down silos). One interviewee expressed a desire for methods that assess the value and quality of design, not just their impact on sustainability (sustainable development consultant 4, 10 September 2013).

Although interviewees were split as to whether methods should consider sustainability holistically, a sub-section of those who favoured the holistic approach wanted greater emphasis on social equity and social justice. This finding speaks to their perception that urban design can be used to exclude sectors of society, restricting access to scarce resources and reinforcing outdated social norms. The interviewees' comments also suggest that the current suite of available methods could be used as part of a larger, creative process for including a greater number and diversity of voices in urban design.

Interviewees' negative comments highlighted that methods can be too detailed and scientific. In some cases, then, the methods become overly prescriptive and assume a solution without the opportunity for built environment professionals and other stakeholders to engage with the bigger 'urban design' picture, thus hindering creativity and innovation.

\subsection{Method operation}

Comments focused on the possibility of making the evidencegathering process less onerous and more transparent, the need for transparency throughout decision making, the importance of allowing time for designs to evolve and the benefits of greater time spent on co-production and co-design (stakeholder input was seen as desirable even if it did not necessarily lead to a better outcome). The latter comment raises the possibility of bringing creativity and innovation into urban design through interesting, fun and ongoing collaboration with a variety of people.

In addition, three interviewees thought that assessment methods should fit naturally within existing urban design 
stages, phases and activities (even though the literature reflects that these are not standardised; see Boyko et al. (2005)).

\section{Characteristics that promote creativity and innovation}

Sawyer (2012) refers to creativity as comprising a little 'c' and a big ' $c$ '. The little ' $c$ ', or individualist approach to creativity, concerns 'a new mental combination that is expressed in the world' (p. 7). The big 'c', or sociocultural approach to creativity, is about 'the generation of a product that is judged to be novel and also to be appropriate, useful, or valuable by a suitably knowledgeable social group' (p. 8). Thus, creativity is not only about generating something unique; it also has to possess utility for people. Furthermore, an understanding of how to make something useful to people is important, which refers directly to innovation: it is a multi-stage process whereby ideas are transformed into new or improved products, services or processes so that the ideas advance, compete or differentiate themselves successfully (Baregheh et al., 2009).

To promote creativity and innovation in urban design a number of characteristics need to exist. These characteristics are not specific to urban design, but may be found in, and adopted from, other professions and disciplines, such as design, design management and business (see Cooper and Press, 1995; Cooper et al., 2011; Perks et al., 2005). According to Amabile et al. (1996), and Bruno-Faria and Alencar (1997), creativity and innovation may be encouraged by the following.

(a) Organisations that promote creativity. They may do this by

(i) fostering risk-taking and idea generation from the lowest to the highest levels of that organisation

(ii) promoting fair and supportive evaluations (i.e. are not critical)

(iii) rewarding and recognising creativity

(iv) allowing for collaborative idea flow across organisational levels and using participative management and decision-making practices.

(b) Supervisors, project managers and leaders that promote creativity. They may do this by

(i) clarifying goals

(ii) interacting openly with people in the lower levels of an organisation

(iii) supporting a team's work and ideas.

(c) Work groups that promote creativity. They may do this by

(i) having a diversity in team members' backgrounds

(ii) supporting mutual openness to ideas

(iii) fostering constructive challenging of ideas

(iv) possessing a shared commitment to a project. (d) Freedom in day-to-day conduct of work and a sense of ownership and control over work and ideas.

(e) Resources to accomplish work (e.g. funds, materials, facilities).

(f) Pressures that promote challenges (e.g. time pressures that foster working hard on challenging tasks and important projects).

The interviewees echoed many of the above characteristics particularly around appropriate skills, a clear starting point, visionary leaders and a good team - and added some new ones, as follows.

(g) Understanding the uniqueness of each design context, including constraints.

(h) Knowing that inspiration may come from elsewhere (e.g. a development in another country).

(i) Community involvement.

(j) A committed and enthusiastic client (e.g. a local authority).

Summarising the above characteristics and thinking more broadly about designing and developing urban environments, eight key characteristics that promote creativity and innovation in urban design emerge, as listed below

risk-taking in idea generation (from $(a),(f)$ and $(g)$ )

visionary leadership (from (b))

team understanding and commitment (from $(b),(c)$ and $(j)$ )

clear, and ideally visionary, brief and strategy (from (b))

access to relevant information and appropriate and sufficient resources (from $(e)$ and $(h)$ )

ownership of ideas (from $(d)$ )

good communication skills, including visualisation and diplomatic skills (from $(a),(b)$ and $(c)$ )

working well with stakeholders outside the design team (from $(i)$ and $(j))$.

\section{Presence of creativity and innovation characteristics in sustainability assessment methods}

No attempt was made during the interviews to define or reach a common understanding of what constituted a sustainability assessment method so as not to influence the interviewees' decisions about which methods they wished to discuss. With that in mind, interviewees identified 32 sustainability assessment methods. The most frequently cited methods were Breeam and Breeam Communities, each mentioned by five interviewees. Design Review Panel was the next most frequently mentioned assessment method, by three interviewees. Casbee, Ceequal, Green Star, Leed, Leed Neighbourhood Development, Passivhaus and SKA Rating were each mentioned by two interviewees, with all 
Urban Design and Planning

Volume 168 Issue DP1
Do sustainability measures

constrain urban design

creativity?

Leach, Boyko, Cooper et al. other assessment methods being mentioned by only one interviewee.

Of the ten assessment methods mentioned more than once, half were not discussed in detail: Casbee, Ceequal, Green Star, Passivhaus and SKA Rating. Of the remaining five, only Design Review Panel and Leed Neighbourhood Development were put forward as supporting creativity and innovation in urban design (see Table 1).

Table 2 shows which of the eight characteristics of creativity and innovation identified in Section 5 are incorporated within the sustainability assessment methods identified by the interviewees. Some interesting points to note can be drawn from this. Of the four methods that display all eight characteristics Design Review Panel, Future Communities, Planning for Real, Urban/Building Futures Game - all operate at a scale above the building level. Aside from the Design Review Panel, Leed Neighbourhood was the only other method promoted by more than one interviewee as having a positive effect upon creativity and innovation. It incorporates three of the characteristics. The most commonly mentioned sustainability assessment methods - Breeam and Breeam Communities - contain one and four characteristics, respectively. The interviewees who mentioned Breeam Communities thought it somewhat hindered creativity and innovation with regard to its prescriptive elements, but it was its lack of robustness at assessing sustainability that prompted the majority of the criticism.

\section{Discussion}

It was apparent from the interviews that an instinctive reaction to rules and regulations - in this case, sustainability assessment methods - is that they stifle creativity and innovation. Interviewees felt that this can be the case particularly if those using or applying them do not properly embrace them and instead resort to ticking boxes and checklists. The danger with rules, regulations and directives is that the designer establishes what is needed to conform, works out the most effective way to achieve this (e.g. practically, with regard to cost) and then proceeds with implementation without properly reflecting on the process of urban design and looking behind or beyond the immediate requirements and normative elements. The interviewees also acknowledged the converse of this argument: rules, regulations, targets or other directives promote deeper thinking on complex issues and that the process of designing can be enhanced by such methods.

Half of the interviewees picked up on the tensions between the ability of assessment methods to engender thinking about complicated issues - providing guiding principles, providing information, possibly providing benchmarks and ideas of what success looks like - with being too prescriptive and driving out creativity and innovation. Interestingly, none of the interviewees suggested sustainability assessment methods should be scrapped, although this may have been because of their perceived value in promoting the sustainability agenda rather than because of any positive impact they have on creativity and innovation in urban design.

There was broad recognition (by eight of the nine interviewees) of the role sustainability assessment methods have in elucidating sustainability issues, providing guidance and benchmarks, thus providing a platform from which urban designers can be creative and innovative. It was in the discussion of specific assessment methods that negative impacts on creativity and innovation prevailed, thus suggesting that those methods currently being applied in practice should be improved upon so they not only positively affect urban sustainability, but also creativity and innovation in urban design.

From the first interview, it became apparent that the use of sustainability assessment methods is inherently complicated and that their efficacy cannot be captured by simple uptake figures (if they existed, which they do not). Interviewees spoke about the difference between the use of an assessment method as it was designed to be used and its use in practice; in some cases the difference was marked. There also was a strong sense that methods are only as good as the person or team using them. This being the case, design teams and their organisations need the capability and capacity to engage with sustainability (and sustainability assessment methods) as well as to be creative and innovative.

The interviewees gave a sense that there was not much perceived difference between many of the sustainability assessment methods currently being applied in practice. Methods such as Breeam, Leed, Casbee and Green Star were discussed in some interviews as if they were almost identical. This may be because there genuinely is little difference between methods. Likewise, built environment professionals may not have a detailed understanding of the plethora of methods on the market and their general or specific use within sustainability, planning and urban design.

Much of what has been discerned from these practitioner views resonates strongly with the experience of the Designing Resilient Cities research team, of which the authors were a part. Designing Resilient Cities was a multi-disciplinary research programme that sought to provide an answer to whether design interventions in cities would likely be resilient in the far future (see Lombardi et al., 2012; Rogers et al., 2012). The Designing Resilient Cities tool (formerly known as the Urban Futures tool), a primary output from the research programme, was identified by one of those interviewed for this paper. The tool operates across scales (urban, neighbourhood and building) and contributes to five of the eight characteristics of creativity and innovation (see Table 2). 
Urban Design and Planning

Volume 168 Issue DP1
Do sustainability measures

constrain urban design

creativity?

Leach, Boyko, Cooper et al.

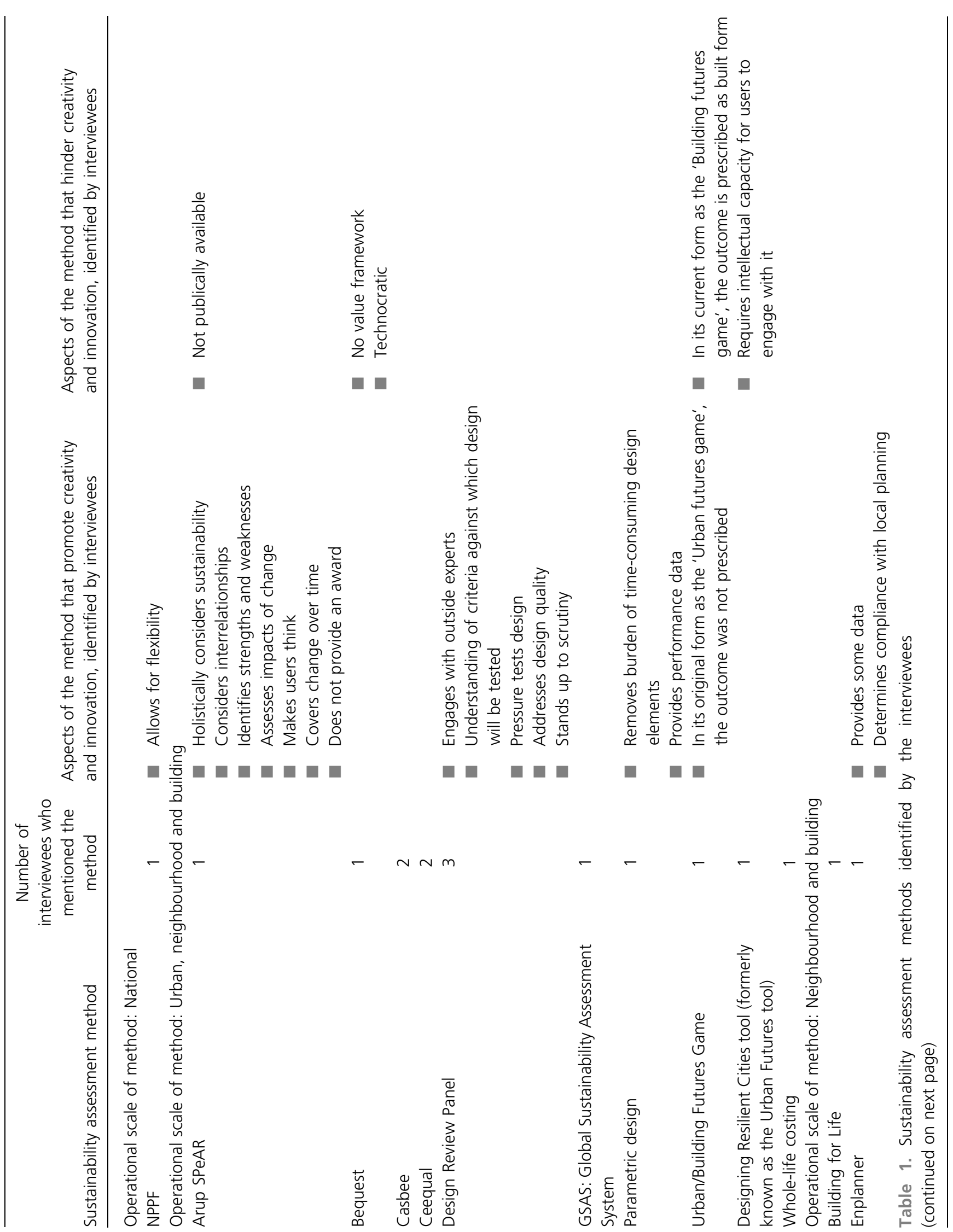


Urban Design and Planning

Volume 168 Issue DP1
Do sustainability measures

constrain urban design

creativity?

Leach, Boyko, Cooper et al.

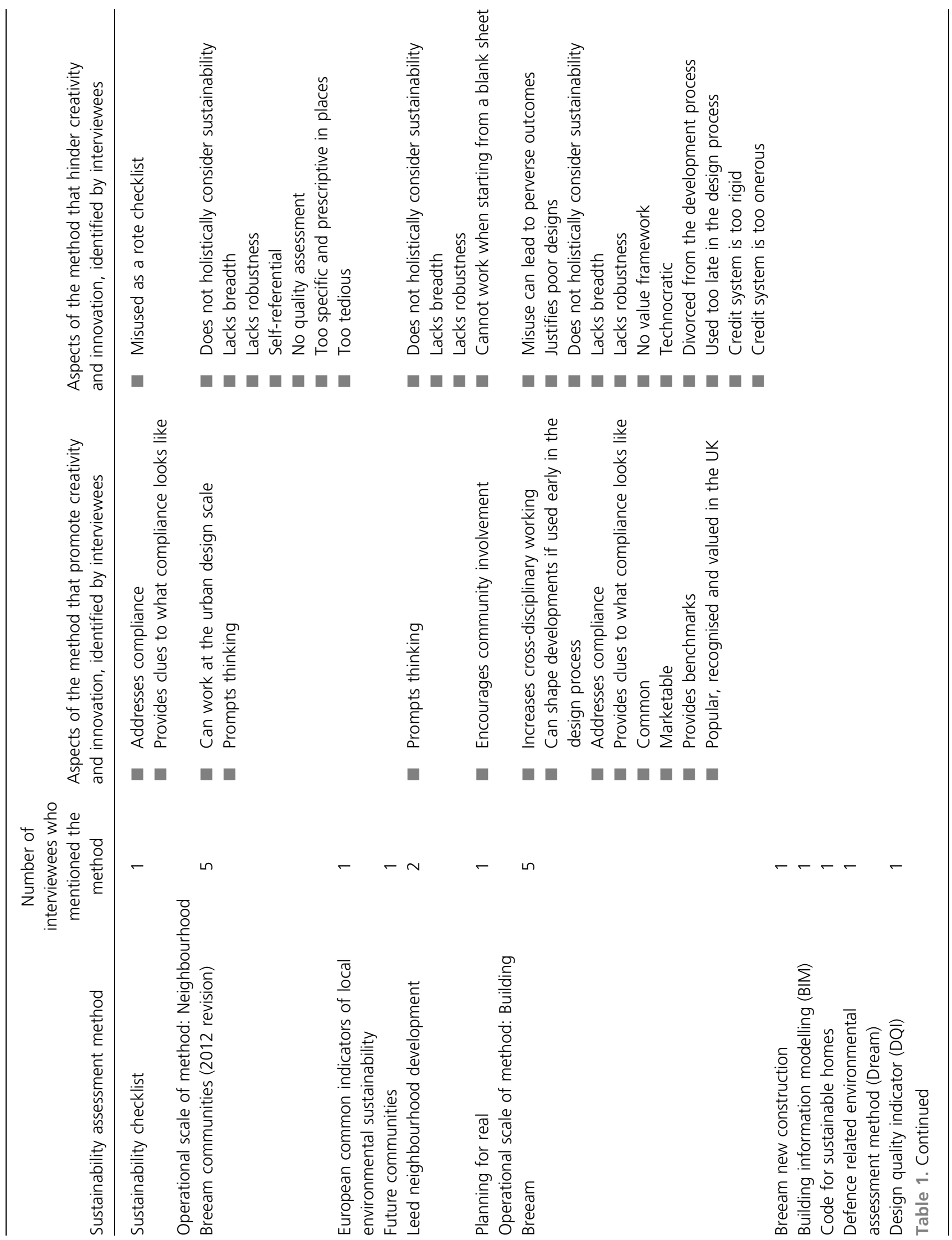


When trialling the tool with a wide range of different practitioner groups (e.g. architects, town planners, engineers), it became apparent that one of its most important features is forcing designers to question their design thinking. Moreover it does not attempt to impose anything, dictate or limit design solutions, or remove responsibility from the designer. In these ways, the tool does not stifle creativity or innovation; rather, it encourages thinking about alternative approaches by raising 'what if?' questions. These ideas were supported by the interviewees, who largely agreed that currently adopted sustainability assessment methods should raise open-ended questions alongside providing guidelines, performance parameters and benchmarks. It is argued that it is for this reason that the Design Review Panel was most positively viewed by the interviewees.

\section{Conclusion}

The insights from nine interviews with UK built environment professionals on the relationship between sustainability assessment methods and creativity and innovation in urban design are revealing, and confirm many of the core findings within urban sustainability research. Interviewees named 32 methods as well as characteristics that promote or hinder creativity and innovation in urban design. The methods were assessed for the presence of eight 'key' characteristics that promote creativity and innovation. From the analysis, it has been possible to establish that sustainability assessment methods do impact creativity and innovation in urban design, and that many current methods are described more negatively than positively in terms of their impact upon creativity and innovation.

There also was broad recognition of the value that sustainability assessment methods have in elucidating sustainability issues and in providing guidance on how they might be addressed. This, in turn, provides a platform from which urban designers can be creative and innovative, both at specific points in the urban design process and throughout the process. Based on the above findings, the authors propose the following principle: a sustainability assessment method will promote creativity and innovation in urban design if it engages competently with sustainability, works at a scale that allows for breadth and depth (typically greater than the building scale), and incorporates a set of eight key characteristics designed to promote creativity and innovation. This principle should guide any new sustainability assessment methods under development.

The findings also suggest that the people creating sustainability assessment methods should think more broadly about those who will use their methods and for what purpose(s). At the moment, many methods appear to be designed to work within a more deterministic, normative, empirical and scientific framework. They either fail to understand or ignore the 


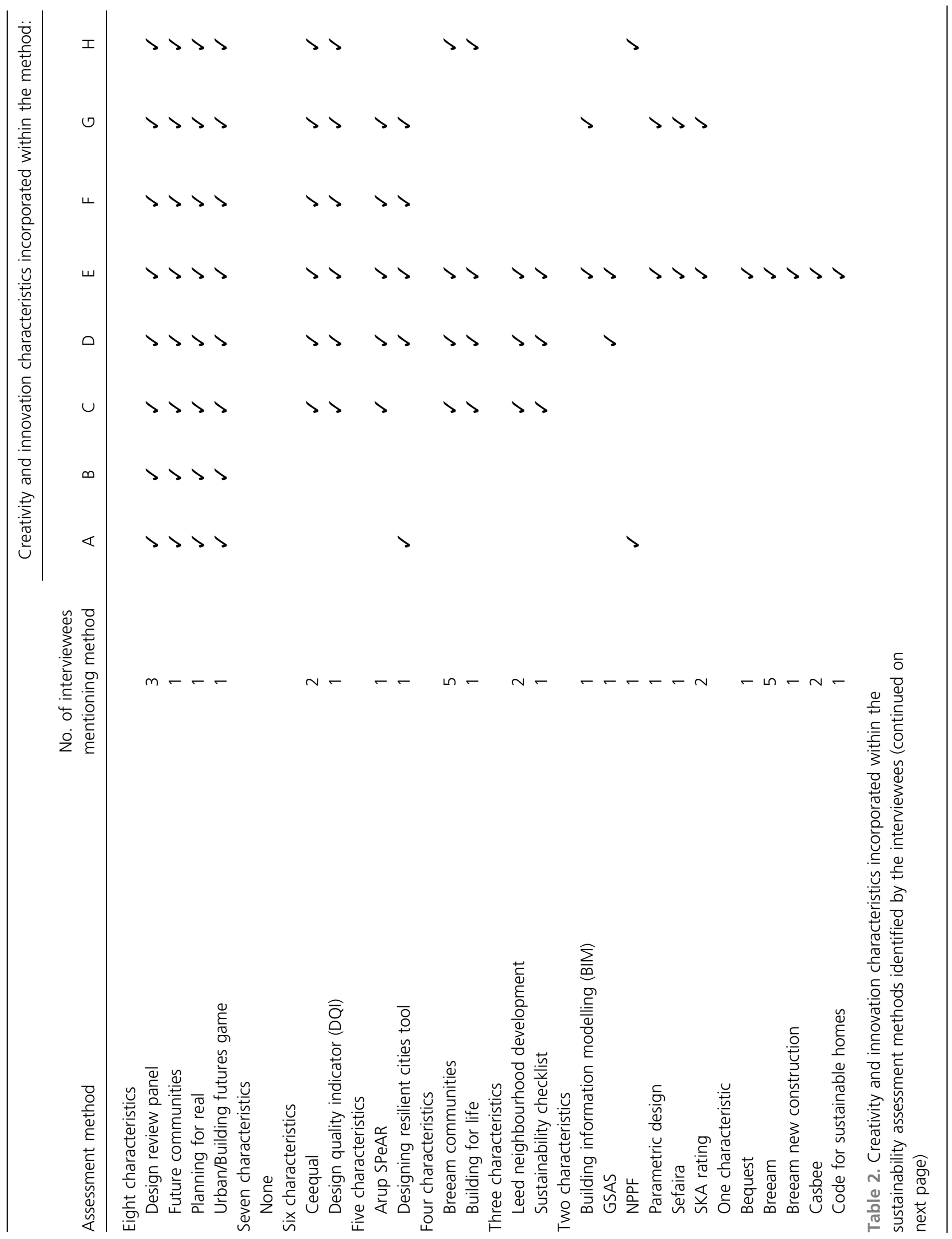


creative and innovative aspects of urban design and the designers who use them (and who work in a more 'designerly' way) (Cross, 1982). Perhaps, when sustainability is more embedded in society, sustainability assessment will naturally encourage creative processes as well as creative and sustainable design solutions.

\section{Acknowledgements}

The authors wish to thank the editors and reviewers for their comments, feedback and guidance in preparing this paper. The authors wish to acknowledge the UK Engineering and Physical Sciences Research Council for its financial support for these research projects under grants EP/F007426 and EP/J017698.

\section{REFERENCES}

Amabile TM, Conti R, Coon H, Lazenby J and Herron M (1996) Assessing the work environment for creativity. Academy of Management Journal 39(5): 1154-1184.

Baregheh A, Rowley J and Sambrook S (2009) Towards a multidisciplinary definition of innovation. Management Decision 47(8): 1323-1339.

Barlow S (2011) Guide to BREEAM. RIBA Publishing, London, UK.

Barnett J (1982) An Introduction to Urban Design. Harper and Row, New York, NY, USA.

Biddulph M (2012) The problem with thinking about or for urban design. Journal of Urban Design 17(1): 1-20.

Boyko CT, Cooper R and Davey C (2005) Sustainability and the urban design process. Proceedings of the Institution of Civil Engineers - Engineering Sustainability 158(3): 119-125.

Brown D (1971) Learning from Pop. Casabella 359-360: 15-46. Brown DS (1990) Urban Concepts. St Martin's Press, New York, USA.

Bruno-Faria MF and Alencar EMLS (1997) Characteristics of an organizational environment which stimulate and inhibit creativity. The Journal of Creative Behavior 31(4): 271-281.

Buchanan P (1988) What city? A plea for place in the public realm. Architectural Review 184(1101): 31-41.

CABE and DETR (Commission for Architecture and the Built Environment and Department of the Environment, Transport and the Regions) (2001) The Value of Urban Design. Thomas Telford, London, UK.

Colman J (1988) Urban design: A field in need of broad educational innovation. Ekistics 55(328-330): 106-109.

Cooper R and Press M (1995) The Design Agenda: A Guide to Successful Design Management. Wiley, Chichester, UK.

Cooper R, Junginger S and Lockwood T (2011) The Handbook of Design Management. Berg, Oxford, UK.

Cowan R (2000) Placecheck: A User's Guide. Urban Design Alliance, London, UK.

Cross N (1982) Designerly ways of knowing. Design Studies 3(4): 221-227. 
Cuthbert A (2010) Whose urban design? Journal of Urban Design 15(3): 443-448.

Cuthbert A (2011) Urban design and spatial political economy. In Companion to Urban Design (Banerjee T and Loukaitou-Sideris A (eds)). Routledge, London, UK, pp. 84-96.

Deakin M, Huovila P, Rao Susheel, Sunikka M and Vreeker R (2002) The assessment of sustainable urban development. Building Research and Information 30(2): 95-108.

DCLG (Department for Communities and Local Government) (2014) Improving the Energy Efficiency of Buildings and Using Planning to Protect the Environment: Code for Sustainable Homes. DCLG, London, UK. See https://www. gov.uk/government/policies/improving-the-energyefficiency-of-buildings-and-using-planning-to-protect-theenvironment/supporting-pages/code-for-sustainable-homes (accessed 18/07/2014).

DETR and CABE (Department of the Environment, Transport and the Regions and Commission for Architecture and the Built Environment) (2000) By Design: Urban Design in the Planning System: Towards Better Practice. Her Majesty's Stationery Office, Norwich, UK.

Ellin N (2013) Integral urbanism: A context for urban design. In Resilience in Ecology and Urban Design: Linking Theory and Practice for Sustainable Cities (Pickett STA, Cadenasso ML and McGrath B (eds)). Springer, Dordrecht, the Netherlands, pp. 63-78.

Floyd J (1978) Urban design... a new profession? Built Environment Quarterly 4(7): 73-77.

Frey H (1999) Designing the City: Towards a More Sustainable Urban Form. E \& F Spon, New York, NY, USA.

Gil J and Duarte JP (2013) Tools for evaluating the sustainability of urban design: A review. Proceedings of the Institution of Civil Engineers - Urban Design and Planning 166(6): 311325, http://dx.doi.org/10.1680/udap.11.00048.

Gosling D (1984) Definitions of urban design. Architectural Design 54(1-2): 31-37.

Kelbaugh D (2002) Typology: An architecture of limits. In Repairing the American Metropolis (Kelbaugh D (ed.)). University of Washington Press, Seattle, WA, USA, pp. 94-132.

Kreditor A (1990) Urban design: A victim of American academic tastes. Center 6: 64-71.

Krieger A (2008) Where and how does urban design happen? In Urban Design (Krieger A and Saunders WS (eds)). University of Minnesota Press, Minneapolis, MN, USA, pp. 113-130.

Lai RT (1988) Law in Urban Design and Planning. Van Nostrand Reinhold, New York, NY, USA.

Lombardi DR, Caserio M, Donovan R et al. (2011) Elucidating sustainability sequencing tensions and tradeoffs in development decision-making. Environmental Planning $B$ 38(6): 1105-1121.
Lombardi DR, Leach JM, Rogers CDF et al. (2012) Designing Resilient Cities: A Guide to Good Practice. IHS BRE Press, Bracknell, UK.

Lynch K (1981) Good City Form. MIT Press, Cambridge, MA, USA.

Madanipour A (1997) Ambiguities of urban design. Town Planning Review 68(3): 363-383.

Marshall R (2009) The elusiveness of urban design: The perpetual problem of definition and role. In Urban Design (Krieger A and Saunders WS (eds)). University of Minnesota Press, Minneapolis, MN, USA, pp. 38-57.

McCreadie M (2006) Client Report: BRE Subcontract: Assessment of Sustainability Tools. BRE, Watford, UK, Report number 15961.

Moughtin C, Cuesta R, Sarris C and Signoretta P (2003) Urban Design: Methods and Techniques, 2nd edn. Architectural Press, Oxford, UK.

Mumford EP and Sarkis H (2008) Jose Lluis Ser: The Architect of Urban Design 1953-1969. Yale University Press, New Haven, CT, USA.

Norberg-Schulz C (1979) Genius Loci: Towards a Phenomenology of Architecture. Rizzoli, New York, NY, USA.

ODPM (Office of the Deputy Prime Minister) (2003) Sustainable Communities: Building for the Future. ODPM, London, $\mathrm{UK}$.

ODPM (2005) Sustainable Communities: People, Places and Prosperity. ODPM, London, UK.

Perks $\mathrm{H}$, Cooper R and Jones C (2005) Characterizing the role of design in new product development: An empirically derived taxonomy. The Journal of Product Innovation Management 22(2): 111-127.

Poveda CA and Lipsett MG (2011) A review of sustainability assessment and sustainability/environmental rating systems and credit weighting tools. Journal of Sustainable Development 4(6): 36-55.

Rogers CDF, Lombardi DR, Cooper RFD and Leach JM (2012) The urban futures methodology applied to urban regeneration. Proceedings of the Institution of Civil Engineers Engineering Sustainability 165(1): 5-20.

Rowley A (1994) Definitions of urban design: The nature and concerns of urban design. Planning Practice and Research 9(3): 179-198.

Sawyer RK (2012) Explaining Creativity: The Science of Human Innovation. Oxford University Press, Oxford, UK.

Schurch TW (1999) Reconsidering urban design: Thoughts about its definition and status as a field or profession. Journal of Urban Design 4(1): 5-28.

Toon J (1988) Urban planning and urban design. Ekistics 55(328-330): 95-100.

Urban Task Force (2005) Towards a Strong Urban Renaissance. Her Majesty's Stationery Office, London, UK. 
Webber PG (ed.) (1988) The Design of Sydney: Three Decades of Change in the City Centre. The Law Book Company, Sydney, Australia.
WCED (World Commission on Environment and Development, Brundtland Commission) (1987) Our Common Future. Oxford University Press, New York, NY, USA.

\section{WHAT DO YOU THINK?}

To discuss this paper, please email up to 500 words to the editor at journals@ice.org.uk. Your contribution will be forwarded to the author(s) for a reply and, if considered appropriate by the editorial panel, will be published as discussion in a future issue of the journal.

Proceedings journals rely entirely on contributions sent in by civil engineering professionals, academics and students. Papers should be 2000-5000 words long (briefing papers should be 1000-2000 words long), with adequate illustrations and references. You can submit your paper online via www.icevirtuallibrary.com/content/journals, where you will also find detailed author guidelines. 